\title{
Association between severity of the temporomandibular disorder, neck pain, and mandibular function impairment
}

\author{
Achilles Motta Nunes ${ }^{1}$ \\ https://orcid.org/0000-0001-7398-2525 \\ Paulo Raimundo Rosário Lopes ${ }^{1}$ \\ https://orcid.org/0000-0003-1388-8988 \\ Marcos Alan Vieira Bittencourt ${ }^{2}$ \\ https://orcid.org/0000-0003-1728-2414 \\ Roberto Paulo Correia de Araújo ${ }^{1}$ \\ https://orcid.org/0000-0001-7648-728X
}

Universidade Federal da Bahia - UFBA, Instituto de Ciências da Saúde, Salvador, Bahia, Brasil.

Universidade Federal da Bahia - UFBA, Faculdade de Odontologia, Salvador, Bahia, Brasil.

Conflict of interests: Nonexistent

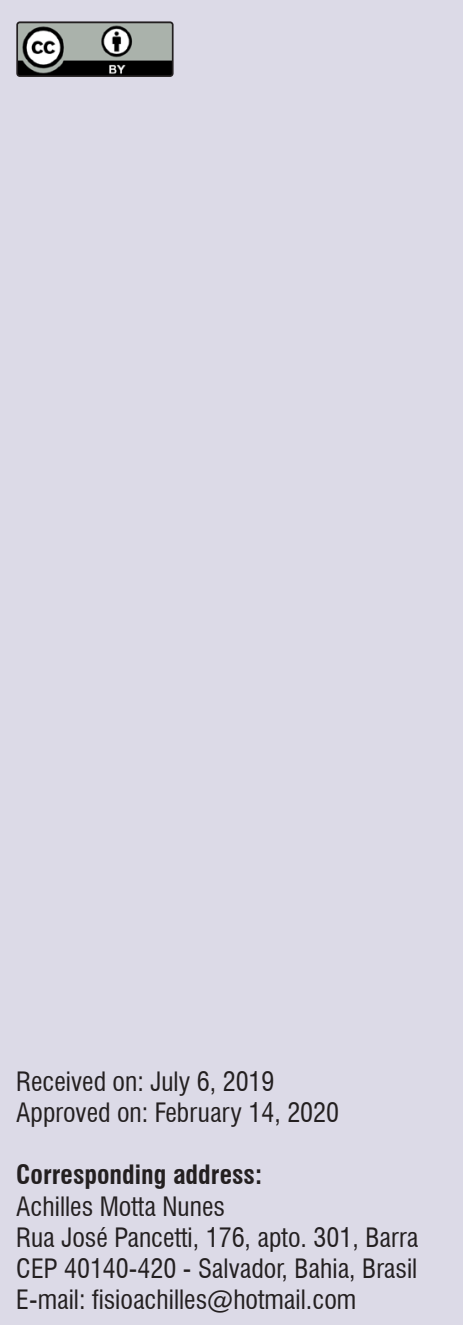

\section{ABSTRACT}

Purpose: to investigate the possible association between the severity of the temporomandibular disorder, cervical pain, and mandibular function impairment.

Methods: is a cross-sectional, descriptive study, conducted with 32 individuals with temporomandibular disorder, categorized by degree of severity, according to the Fonseca Index. Using the diagnosis criteria for temporomandibular disorder, the likely etiological factors for the disorder were established, as well as the intensity of the functional disability, resulting from cervical pain and of the mandibular impairment. The data obtained were statistically treated, adopting the significance level of $5 \%$.

Results: the mean age was 33.8 years, $90.6 \%$ being females. As for the degree of disorder, $56.3 \%$ presented severe TMD, followed by $28.1 \%$ showing a moderate one. The myogenic etiology was present in $93.7 \%$ of the patients. Cervical pain was present in $90.6 \%$ of them, of which, $59.4 \%$ presented a mild disability, and $25 \%$, a moderate one. Considering the mandibular function, $46.9 \%$ of the patients presented a low, $40.6 \%$, a moderate, and $12.5 \%$, a severe impairment. There was a statistically significant association between cervical pain and mandibular function $(p=0.011)$. However, although there was an increase in cervical disability and in mandibular impairment as the severity of the TMD also increased, these associations were not statistically significant ( $p=0.178$ and $p=0.102$, respectively).

Conclusion: it can be stated that there is a higher prevalence of severe TMD and of myogenic origin, and that cervical pain influences, directly, the mandibular function, which is not necessarily related to the severity of the temporomandibular alteration. Likewise, such severity does not present a relationship to mandibular function impairment either.

Keywords: Temporomandibular Joint; Temporomandibular Joint Disorder Syndrome; Cervical Pain 


\section{INTRODUCTION}

The temporomandibular joint (TMJ) is one of the most used joints of the human body, as it participates in phonation, chewing and swallowing ${ }^{1}$. Since it works harmoniously in a paired system, with synchronicity and functionality, it must be seen not only as a component of these functions, but also as a structure related to the respiratory and postural systems. Such relation refers to its anatomical proximity to the cervical spine and to the shoulder girdle, through a common myoneural junction system ${ }^{1-3}$, in which the positions are interrelated, characterizing a functional unit ${ }^{3}$. Alterations in their components' position or function can lead to interferences not only in the stomatognathic system, but also in the postural one, potentially bringing about a process of biomechanical disadvantage ${ }^{4-6}$.

The temporomandibular disorder (TMD) is a set of conditions characterizing structural and/or functional alterations of the masticatory system, involving articular and muscular components ${ }^{6}$. As it is marked by various signs and symptoms, e.g., increased pain sensitivity in the cervical and masticatory muscles, articular noise, mandibular function irregularities, and even blocking of movements, TMD is considered a disorder of the masticatory-cervical muscle complex ${ }^{7}$. Its etiology is multifactorial, for there are systemic, psychological (psychobehavioral) and structural (dentofacial alterations, ligamentous laxity) factors that can lead to postural head and neck diosrders ${ }^{8}$. The temporal and masseter muscles' hyperactivity, bruxism and stress can increase jaw clenching, overloading the articulations and becoming risk factors ${ }^{9}$.

The postural alterations can also contribute to developing or perpetuating the TMDs. Studies report that deviations such as forward head posture, cervical spine rectification and shoulder asymmetry influence on their emergence. The neuromuscular control of chewing and of the cervical region participates actively in cervical spine positioning and jaw movements, potentially causing functional alterations when one of them is affected $^{10}$.

According to the Sociedade Brasileira para o Estudo da Dor (in English, Brazilian Society for Pain Studies), cervical pain affects from $30 \%$ to $50 \%$ of the population and is one of the predominant pain complaints in medical practice ${ }^{11}$. When it is present, it causes antalgic posture, which can directly influence the temporomandibular biomechanics, as the joint, when affected, seeks for a more comfortable posture to avoid pain. Hence, the cervical spine posture influences directly on the face, with a role in the relation between the maxilla and the mandible ${ }^{10,12}$. Cervical muscle spasm has various causes, but it can also be a painful condition caused by the TMD, making the palpation of the upper trapezius and sternocleidomastoid muscles more uncomfortable. Perhaps, for this reason, the pressure pain threshold of the cervical muscles, observed through algometry, is lower in individuals with TMD than in those without dysfunction, corroborating the idea that there is an association between them ${ }^{13}$.

Since there is such compensatory pattern due to pain, with antalgic postures being adopted to minimize its perception, this study, in addition to verifying the prevalence of pain conditions in the cervical region in patients with TMD, aimed at observing the association between cervical pain, the severity of the dysfunction and the possible mandibular function impairment. The hypothesis investigated was the existence of an association between TMD severity and cervical pain, between TMD severity and mandibular function, and between cervical pain and mandibular function. The understanding of the association between these events can make the therapeutic approach more direct, including the handling of the cervical region as an additional possibility to control the pain condition in individuals with TMD symptoms, which can significantly influence the treatment results.

\section{METHODS}

This study was approved by the Research Ethics Committee of the Instituto de Ciências da Saúde of the Universidade Federal da Bahia, under evaluation report no. 1.007.712. Complying with Resolution no. 466/12 of the Conselho Nacional de Saúde (CNS/MS), all the patients were duly informed of the objectives of this research and agreed to participate in it, having signed the Informed Consent Form (ICF).

This is a descriptive cross-sectional study with a nonprobabilistic sample, initially conducted with 123 individuals with TMD symptoms, screened at the Magalhães Neto Pain Outpatient Clinic of the Hospital Universitário Professor Edgard Santos, of the Clínica Escola da Faculdade de Odontologia da Universidade Federal da Bahia - UFBA, BA, Brazil. The participants were either referred by health professionals or attended spontaneously after the study had been announced in posters.

The STROBE tool was used to assist in conducting the research and disclosing the results. The recruitment of the sample and the data collection took place from 
February to August 2016. Patients of both genders, aged from 18 to 60 years, were included. Individuals with rheumatologic diseases, spondylosis, tumors or metastases, bone tuberculosis, neuropsychomotor or cognitive alterations that hindered them when answering the questionnaire, as well as those who had previously suffered craniofacial and/or cervical trauma, who had been submitted to craniomandibular and/or cervical surgical-orthopaedical treatments, or who were simultaneously undergoing treatment of the cervical region (with medications, physiotherapy, massotherapy, speech-language therapy or others) were excluded from the research.

All the patients were instructed to undergo clinical anamnesis and sociodemographic evaluation. For this study, the following tools were used: 1) Fonseca Anamnesis Index 14; 2) Research Diagnostic Criteria for Temporomandibular Disorders ${ }^{15,16}$; 3) Neck Pain-Related Disability Index ${ }^{17}$, and; 4) Mandibular Function Impairment Questionnaire ${ }^{18}$. The instruments used as interviews, as well as the physical examinations, were conducted by the two main researchers, previously trained and calibrated physiotherapists. The assessments lasted 40 minutes on average.

The Fonseca Anamnesis Index (FAl), as it presents adequate reliability and validity, was used to classify and characterize the severity of the TMD symptoms ${ }^{14,19}$. It is composed of 10 questions, for each of which three answers are possible - no, sometimes and yes; each answer has a pre-established score $-0,5$ and 10 , respectively. As the points given are added, an index is obtained which enables the patients to be classified in four different categories: without TMD, mild TMD, moderate TMD, and severe TMD.

The Research Diagnostic Criteria for Temporomandibular Disorders (RDC/TMD), created by Dworkin and LeResche $(1992)^{15}$ and validated in Portuguese by Lucena et al. $(2006)^{16}$, is widely used for the diagnosis and classification of the most common types of TMD. It has a double axis system, enabling clinical aspects to be analyzed, placed in Axis 1 , as well as the psychological and psychosocial factors, placed in Axis 2; thus, according to etiology, it is possible to categorize it as muscular, discal and articular. To measure more precisely the amplitude of mandibular movement, a stainless-steel precision digital pachymeter was used (ZAAS Precision $150 \mathrm{~mm}$, Amatools, Piracicaba, São Paulo, Brazil).

The Neck Pain-Related Disability Index (NDI), idealized by Vernon and Mior $(1991)^{20}$, was adapted to Portuguese by Cook et al. (2006) ${ }^{21}$ and validated by Pereira et al. (2015) ${ }^{17}$. It is used to assess the degree of functional impairment of the cervical region associated with acute or chronic pain situations. It is composed of 10 sessions with six answers each, totaling a maximum of 50 points. The value obtained is expressed in percentages, enabling the classification in five categories: without disability, or with mild, moderate, severe or complete disability.

The Mandibular Function Impairment Questionnaire (MFIQ), created by Stegenga et al. (1993) ${ }^{18}$, has a scoring system that characterizes it as an index, making it possible to classify the severity of TMD-related function impairment ${ }^{18}$. It presents 17 questions, to which five answers are possible. The total score is obtained by adding the values of the answers to each question. The coefficient obtained is confronted with conditions of the set of answers in order to obtain the level of the affection, which can be either low, moderate or severe.

The databank was created in Excel 2007 and analyzed through R 3.3.1 software. Both the absolute and relative frequencies were analyzed for the measures in the qualitative scale and, to verify the association between nominal variables, Fisher's exact test was used. The significance level established was $5 \%$.

\section{RESULTS}

After screening, 91 of the 123 patients that had enrolled to be attended at the physiotherapy outpatient center of the institution of origin were excluded based on the previously defined criteria. Of these, 24 could not be reached through the phone number they had given; 14 had recently undergone orthognathic surgery and were in the postoperative period; 13 had started the physiotherapeutic approach to TMD, including techniques for the cervix; 11 presented a diagnosis of cervical dysfunction (spondyloarthritis and cervical hernia); nine abandoned the research still in its first stage; three were diagnosed with fibromyalgia; three were undergoing preoperative examinations for orthognathic surgery; three were treating TMD at other institutions; three presented another diagnosis (altered phonation), two were presented cognitive alteration; two were diagnosed with fractured mandible; one presented an acute condition of rheumatoid arthritis; one was undergoing dental treatment; one had facial palsy, and, lastly; one patient presented Eagle syndrome. Thus, after applying the exclusion criteria, 
the sample selected to conduct the research totaled 32 patients. There was a predominance of female patients, as there were 29 women $(90.6 \%)$ and only three men $(9.4 \%)$, mean age 33.8 years $(S D=11.39)$.

The clinical characteristics presented by the patients after assessment through the $\mathrm{FAI}, \mathrm{RDC} / \mathrm{TMD}, \mathrm{NDI}$, and
MFIQ are seen in Table 1. Regarding the RDC/TMD, it should be highlighted that each individual presented at least one etiological factor. However, when the possibility of another factor was verified, it was observed that 22 patients had two or three possible etiologies (Table1).

Table 1. Clinical characteristics of the study population, assessed by means of the diagnostic tools used

\begin{tabular}{|c|c|c|}
\hline Variables & $\mathrm{n}=32$ & $\%$ \\
\hline \multicolumn{3}{|l|}{ FAI } \\
\hline Without TMD & 1 & 3.1 \\
\hline Mild TMD & 4 & 12.5 \\
\hline Moderate TMD & 9 & 28.1 \\
\hline Severe TMD & 18 & 56.3 \\
\hline \multicolumn{3}{|l|}{ RDC/TMD } \\
\hline Without TMD & 1 & 3.1 \\
\hline One etiology & 9 & 28.1 \\
\hline Two etiologies & 18 & 56.3 \\
\hline Three etiologies & 4 & 12.5 \\
\hline \multicolumn{3}{|l|}{ Muscular RDC/TMD } \\
\hline Did not have expression & 2 & 6.3 \\
\hline Had expression & 30 & 93.7 \\
\hline \multicolumn{3}{|l|}{ Discal RDC/TMD } \\
\hline Did not have expression & 26 & 81.3 \\
\hline Had expression & 6 & 18.7 \\
\hline \multicolumn{3}{|l|}{ Articular RDC/TMD } \\
\hline Did not have expression & 11 & 34.4 \\
\hline Had expression & 21 & 65.6 \\
\hline \multicolumn{3}{|l|}{ NDI } \\
\hline Without disability & 3 & 9.4 \\
\hline Minimal disability & 19 & 59.4 \\
\hline Moderate disability & 8 & 25.0 \\
\hline Severe disability & 1 & 3.1 \\
\hline Complete disability & 1 & 3.1 \\
\hline \multicolumn{3}{|l|}{ MFIQ } \\
\hline Low & 15 & 46.9 \\
\hline Moderate & 13 & 40.6 \\
\hline Severe & 4 & 12.5 \\
\hline
\end{tabular}

FAl, Fonseca Anamnesis Index; RDC/TMD, Research Diagnostic Criteria for Temporomandibular Disorders; NDI, Neck Disability Index; MFIQ, Mandibular Function Impairment Questionnaire. 
In Tables 2, 3, and 4, the result of the association between the qualitative variables used to categorize the TMD is verified. In Table 2, where the association between severity of TMD (FAl) and cervical pain (NDI) is seen, it is observed that, though it was not statistically significant $(p=0.178)$, cervical disability increased as the severity grew more intense. In the association between TMD severity (FAl) and mandibular function
(MFIQ) (Table 3), a direct growth proportion was verified, although without statistical significance ( $p$ $=0.102$ ) as well. On the other hand, when cervical pain (NDI) was associated with mandibular function impairment (MFIQ) (Table 4), a directly proportional, statistically significant $(p=0.011)$ relationship was observed.

Table 2. Association between the severity of Temporomandibular Disorder (Fonseca Anamnesis Index) and cervical pain (Neck Disability Index)

\begin{tabular}{|c|c|c|c|c|c|c|c|c|c|c|c|}
\hline \multirow{3}{*}{ Variables } & \multicolumn{11}{|c|}{ NDI } \\
\hline & \multicolumn{2}{|c|}{$\begin{array}{c}\text { Without } \\
\text { disability }\end{array}$} & \multicolumn{2}{|c|}{$\begin{array}{c}\text { Minimal } \\
\text { disability }\end{array}$} & \multicolumn{2}{|c|}{$\begin{array}{l}\text { Moderate } \\
\text { disability }\end{array}$} & \multicolumn{2}{|c|}{ Severe disability } & \multicolumn{2}{|c|}{$\begin{array}{l}\text { Complete } \\
\text { disability }\end{array}$} & \multirow[t]{2}{*}{ P-value } \\
\hline & $n$ & $\%$ & $\mathbf{N}$ & $\%$ & $n$ & $\%$ & $n$ & $\%$ & $n$ & $\%$ & \\
\hline \multicolumn{12}{|l|}{ FAI } \\
\hline Without TMD & - & - & 1 & 100.0 & - & - & - & - & - & - & \multirow{3}{*}{0.178} \\
\hline Mild TMD & 2 & 50.0 & 2 & 50.0 & - & - & - & - & - & - & \\
\hline Moderate TMD & - & - & 8 & 88.9 & 1 & 11.1 & - & - & - & - & \\
\hline Severe TMD & 1 & 5.6 & 8 & 44.4 & 7 & 38.8 & 1 & 5.6 & 1 & 5.6 & \\
\hline
\end{tabular}

Legend: NDI: Neck Disability Index; FAl: Fonseca Anamnesis Index; TMD: Temporomandibular Disorder

Fisher's exact test

Table 3. Association between the severity of the temporomandibular disorder (Fonseca Anamnesis Index) and the mandibular function impairment (Mandibular Function Impairment Questionnaire)

\begin{tabular}{|c|c|c|c|c|c|c|c|}
\hline \multirow{3}{*}{ Variables } & \multicolumn{7}{|c|}{ MFIQ } \\
\hline & \multicolumn{2}{|c|}{ Low } & \multicolumn{2}{|c|}{ Moderate } & \multicolumn{2}{|c|}{ Severe } & \multirow{2}{*}{ P-value } \\
\hline & $n$ & $\%$ & $n$ & $\%$ & $\mathrm{n}$ & $\%$ & \\
\hline \multicolumn{8}{|l|}{ FAI } \\
\hline Without TMD & 1 & 100.0 & - & - & - & - & \\
\hline Mild TMD & 4 & 100.0 & - & - & - & - & 0.102 \\
\hline Moderate TMD & 5 & 55.6 & 4 & 44.4 & - & - & \\
\hline Severe TMD & 5 & 27.8 & 9 & 50.0 & 4 & 22.2 & \\
\hline
\end{tabular}

Legend: MFIQ: Mandibular Function Impairment Questionnaire; FAl: Fonseca Anamnesis Index; TMD: Temporomandibular Disorder Fisher's exact test

Table 4. Association between cervical pain (Neck Disability Index) and the mandibular function impairment (Mandibular Function Impairment Questionnaire)

\begin{tabular}{|c|c|c|c|c|c|c|c|}
\hline \multirow{3}{*}{ Variables } & \multicolumn{7}{|c|}{ MFIQ } \\
\hline & \multicolumn{2}{|c|}{ Low } & \multicolumn{2}{|c|}{ Moderate } & \multicolumn{2}{|c|}{ Severe } & \multirow{2}{*}{ P-value } \\
\hline & $\mathbf{n}$ & $\%$ & $\mathrm{n}$ & $\%$ & $n$ & $\%$ & \\
\hline \multicolumn{8}{|l|}{ NDI } \\
\hline Without disability & 3 & 100.0 & - & - & - & - & \multirow{5}{*}{0.011} \\
\hline Minimal disability & 10 & 52.6 & 9 & 47.4 & - & - & \\
\hline Moderate disability & 2 & 25.0 & 3 & 37.5 & 3 & 37.5 & \\
\hline Severe disability & - & - & 1 & 100.0 & - & - & \\
\hline Complete disability & - & - & - & - & 1 & 100.0 & \\
\hline
\end{tabular}

Legend: MFIQ: Mandibular Function Impairment Questionnaire; NDI: Neck Disability Index

Fisher's exact test 


\section{DISCUSSION}

The aim of this study was to verify the possible association between the qualitative variables used to categorize the TMD, the pain condition in the cervical region and the mandibular function movements. The data obtained show that, in patients with TMD, the disability of cervical function, whose main element is pain, was present in $90.6 \%$ of the patients examined, whereas the mandibular function impairment, with restricted jaw movements, was observed in all of them. This very significant result reinforces the idea of the quite close relation between the three conditions. Nevertheless, of the hypotheses outlined for this study, there was a statistically significant association only between cervical pain and mandibular function, demonstrating that the greater the cervical disability greater was the mandibular impairment.

There was an expressive predominance of women, with a prevalence of $90.6 \%$. In the literature ${ }^{13,22}$, the greater prevalence of females has also been reported, in a proportion of ranging from 3:1 to 9:1. Donnarumma et al. $(2010)^{23}$ reported a female predominance of $85.6 \%$ of the sample, Corrêa et al. (2011) ${ }^{6}$ found $90 \%$, Portinho et al. $(2012)^{24}, 85.2 \%$, and Ferreira et al. $(2016)^{25}, 82,3 \%$. Ciacanglini et al. (1999) ${ }^{26}$ explain that such difference occurs in part due to the women's being more concerned with their health and seeking specialized services earlier and in greater numbers than men. Furthermore, there is the hormonal issue, as the women present greater ligament laxity and have more flexible and less dense articulations than $\operatorname{men}^{25}$. The mean age of 33.8 years in this study was similar to that reported by other authors. Donnarumma et al. $(2010)^{23}$ found mean age of 35 years, Portinho et al. (2012) ${ }^{24}$, 38.9 years, Ferreira et al. $(2016)^{25}, 33.04$ years and, lastly, Torres et al. (2012) ${ }^{27}, 34.3$ years, with descriptions in the literature showing greater prevalence of TMD between 20 and 40 years old.

Among the patients with TMD symptoms selected for this research, the greatest prevalence verified was of severe TMD, present in $56.3 \%$, followed by moderate in $28.1 \%$. Likewise, Torres et al. $(2012)^{27}$ verified that $60 \%$ of the patients had severe TMD, and $40 \%$, moderate. On the other hand, the descriptive analysis by Biasotto-Gonzalez et al. (2008) ${ }^{28}$ demonstrated that $68.36 \%$ of those composing the sample presented mild dysfunction, $23.47 \%$, moderate, and only $8.16 \%$, severe. Greater prevalence of mild TMD was also described by Corrêa et al. $(2011)^{6}$, in $49.5 \%$ of the patients, by Nunes et al. $(2015)^{29}$, in $49.12 \%$, and by Menezes et al. $(2008)^{30}$, in $46.1 \%$. It should be highlighted that the abovementioned studies, which presented a greater prevalence of the mild degree, were conducted with a sample composed of university students, and not by individuals with symptoms and/ or diagnosis of TMD who had sought for attention at specialized services. Moreover, all the studies mentioned Fonseca's questionnaire (FAl) as an easyto-use instrument in categorizing the TMD severities.

Using RDC/TMD, although more complex, is also very important to identify the likely etiological factors of TMD. Filling in the questionnaire takes a long time and requires a lot of attention, besides employing an algorithm to categorize them. In this paper, the presence of more than one etiology was verified in most of the patients, $56.3 \%$ of them presenting two etiologies, and $12.5 \%$, three. In a similar analysis, Pozzebon et al. $(2016)^{13}$ found very similar values, the mixed etiology being present in $53.85 \%$ of the patients. Milanesi et al. $(2013)^{31}$ found the little smaller, yet still relevant value of $46.9 \%$ presenting two etiologies. As for structure, muscular impairment was present in $93.7 \%$ of the patients in this research, whereas articular and discal alterations were present in $65.6 \%$ and $18.7 \%$, respectively. Milanesi et al. (2013) ${ }^{31}$ published a similar prevalence, with $87.5 \%$ of the sample presenting myogenic TMD. On the other hand, Pozzebon et al. (2016) ${ }^{13}$ reported a lower value of patients with myogenic TMD, which was present in only $46.15 \%$ of the sample.

As said before, the cervical function was impaired in the great majority of the patients with TMD, demonstrating the proximity there is between these two conditions. Such relation is also mentioned by other authors, who stated that most of the patients with TMD presented pain in other parts of the body, of which the cervical region was the most affected; this finding is of great relevance for clinical practice ${ }^{7,32,33}$. Hence, analyzing the results of this likely association in the present research, it was observed that, even though there was no statistical significance $(p=0.178)$, the cervical disability is aggravated in the proportion that TMD severity is increased; i.e., patients with severe or moderate TMD tend to present greater cervical impairment than patients with mild TMD (Table 2). Similarly, BevilaquaGrossi et al. (2007) ${ }^{10}$ described that, when evaluating signs and symptoms of cervical pain in women with TMD, they found a directly proportional association between them. A possible justification for these findings is the fact that individuals with TMD in general present alterations in the chewing pattern, as the affection of the 
anterior temporal muscle and the nociceptive stimuli of the craniomandibular region influence the increase in activation asymmetry of this musculature, causing unbalance and consequent dysfunction ${ }^{7}$. In addition, individuals with orofacial pain in the masticatory musculature tend to present greater neck muscle deficiency ${ }^{34}$. However, all these authors highlight that the influence of the degree of severity and the duration of craniomandibular and cervical pain, both in TMD and in using the masticatory muscles, need to be better investigated.

Regarding the mandibular function, it is known that individuals with TMD present alteration in the masticatory pattern, since nociceptive stimuli of the craniomandibular region can influence in the increase of activation asymmetry of the masticatory musculature, triggering the mandibular dysfunction ${ }^{7}$. In this research, while searching for the association between TMD severity and mandibular function (Table 3), a direct growth proportion was observed between them. Patients without TMD or with mild TMD presented little mandibular impairment. Among the individuals with moderate TMD, 55.6\% presented low impairment and $44.4 \%$ had a moderate impairment. As for the group of patients with severe TMD, $27.8 \%$ presented little impairment, $50 \%$, moderate impairment, and $22.2 \%$, severe mandibular function impairment. This interpretation suggests an aggravation of the mandibular function as the TMD severity is increased. Nonetheless, after statistical analysis, such association was not significant $(p=0.102)$. When evaluating the type of restriction of mandibular function, Portinho et al. $(2012)^{24}$ reported that $38.9 \%$ of the patients assessed presented mandibular deviations in opening and closing it, $22.2 \%$ had articular instability, $14.8 \%$ had jaw locking, and $11.1 \%$ presented subluxation.

When approaching the mandibular function rehabilitation by means of manual therapy techniques in patients with TMD, Silva et al. $(2011)^{35}$ cited the use of physiotherapy with cervical joint repositioning and concluded that such approach was effective not only to increase the amplitude of mandible movement but also to decrease the cervical pain condition. Oliveira et al. $(2010)^{36}$ stood in consonance with them, affirming the close relation of the cervical spine to the TMJ, and reporting kinesiotherapy, manual therapy, and cervical stabilization as important physiotherapeutic approaches. In this study, the mandibular function impairment was present in all the patients assessed. When its relation to cervical pain was sought for (Table 4), a directly proportional and statistically significant relation was observed between them $(p=0.011)$, with greater mandibular function impairment as the cervical disability presented by the patient was more severe. It was observed that individuals without a cervical disability presented little mandibular function impairment, whereas those who had a complete cervical disability presented great incapacity. In consonance with this result, Rosa et al. (2011) ${ }^{37}$ described that the movement restriction caused by orofacial pain of muscular origin can also make evident the likely involvement of the cervical joint structures, impairing the mandibular function. Viana et al. (2015) ${ }^{38}$ verified that the increase in cervical lordosis seems to cause greater difficulty to open the mouth, reinforcing the close relationship between cervical pain and mandibular dysfunction.

It is important to emphasize that the relationship between the cervical region and the TMJ seems to result from the anatomical and neurophysiology interaction there is between them, and isolated alterations in each function (breathing, phonation, chewing, swallowing) interfere with the physiology of the whole stomatognathic system ${ }^{37}$. Furthermore, pain in the orofacial region can impair the functioning of the cervical region ${ }^{39}$. For Weber et al. (2012) ${ }^{40}$, the diagnosis of TMD evidenced a greater frequency of cervical pain and smaller amplitude of mandibular movement, probably more as a consequence of the common innervation of the trigeminocervical complex and of the hyperalgesia of the individuals with TMD, than of the craniocervical posture alteration. On the other hand, Tosato e Caria $(2007)^{33}$ stated that any postural alteration in the cervical region can lead to a modification in the TMJ biomechanics since the jaw is a movable bone; i.e., cervical pain can lead to an antalgic head posture, altering the mandibular movement. Thus, due to this relationship between cervical pain and TMD, it is suggested that the data about the cervical region be considered by all the professionals treating TMJ, with an approach that goes beyond the orofacial region.

This study was limited due to its sample size, as the physiotherapy service where the data was collected is not center specialized in dealing with patients with TMD or orofacial pain. Even with the extensive announcement, the presence of individuals meeting the inclusion criteria was small. The exclusions were in great numbers, especially as a consequence of the strictness of the criteria in the attempt to eliminate as much as possible the confounding aspects. The reduced number of individuals in some categories of 
the variables studied can have disguised the statistical relevance of associations proposed in this study.

On the other hand, as there is a close relationship between the anatomical proximity and the musculature involving the cervical, mandibular and TMJ regions, this study sought to establish an interdependence between the function alterations presented by these structures, contributing to the scientific growth in this area. Although a greater relationship has been verified between the pain processes in the cervical region and the alterations in mandibular function, the TMD severity also seemed to be closely related. Hence, the actual improvement in the quality of life of the patients with TMD must be obtained through a therapeutical approach that also includes stretching and strengthening exercises for the cervical musculature, besides articular maneuvers in the TMJ and in the cervical spine.

\section{CONCLUSION}

In this study, in accordance with the methodology employed, it was verified that cervical pain was present in $90.6 \%$ of the patients with TMD assessed. However, when the association between these two conditions was evaluated, it was noted that, even though cervical pain grew in intensity as the degree of TMD severity increased, there was no statistically significant association. The same occurred when the association between TMD severity and mandibular function was evaluated. On the other hand, a statistically significant association between cervical pain and mandibular function was noted, there being greater mandibular function impairment in patients with greater cervical disability.

\section{REFERENCES}

1. Bricot B. Posturologia clínica. 1 ed. São Paulo: Ícone; 2011.

2. Moraes AR, Sanches ML, Ribeiro EC, Guimarães AS. Therapeutic exercises for the control of temporomandibular disorders. Dent Press J Orthod. 2013;18(5):134-9.

3. Liao Giovanetti CO. Estudo da pressão plantar em indivíduos com e sem dor temporomandibular antes e depois de uma intervenção fisioterapêutica manual na coluna cervical [dissertação]. Guaratinguetá (SP): Faculdade de Engenharia de Guaratinguetá da Universidade Estadual Paulista; 2009.
4. Amantéa DV, Novaes AP, Campolongo GD, Barros TP. A importância da avaliação postural no paciente com disfunção da articulação temporomandibular. Acta Ortop Bras. 2004;12(3):155-9.

5. Ries LG, Bérzin F. Analysis of the postural stability in individuals with or without signs and symptoms of temporomandibular disorder. Braz Oral Res. 2008;22(4):378-83.

6. Corrêa EG, Capeletti AM, Dega MR, Papa LP. Disfunção têmporo-mandibular e avaliação postural: uma abordagem interdisciplinar. Rev Eletrônica Saúde: Pesquisa e Reflexões. 2011;1(1): 1-7

7. Ries LGK, Graciosa MD, Medeiros DL, Pacheco SCS, Fassicolo CE, Graefling BCF et al. Influence of craniomandibular and cervical pain on the activity of masticatory muscles in individuals with Temporomandibular Disorder. CoDAS. 2014;26(5):389-94.

8. Matta MAP, Honorato DC. Uma abordagem fisioterapêutica nas desordens temporomandibulares: estudo retrospectivo. Rev Fisioter Univ São Paulo. 2003;10(2):77-83.

9. Nicolakis $P$, Erdogmus $B$, Kopf $A$, Djaber-Ansari A, Piehslinger E, Fialka-Moser V. Exercise therapy for craniomandibular disorders. Arch Phys Med Rehabil. 2000;81(9):1137-42.

10. Bevilaqua-Grossi D, Chaves TC, Oliveira AS. Cervical spine signs and symptoms: perpetuating rather than predisposing factors for temporomandibular disorders in women. J Appl Oral Sci. 2007;15(4):259-64.

11. Silva MC, Fonseca MS, Cardoso RK, Spieker CV. Problemas musculoesqueléticos em docentes e servidores de um Curso de Educação Física do Rio Grande do Sul/Brasil. R Bras Ci Saúde. 2014;18(2):115-20.

12. Tosato JP, Gonzalez TO, Sampaio LMM, Corrêa JCF, Biasotto-Gonzalez DA. Prevalência de sinais e sintomas de disfunção temporomandibular em mulheres com cervicalgia e lombalgia. Arq Med ABC. 2008;32(Supl. 2):S20-2.

13. Pozzebon D, Piccin CF, Silva AMT, Correa ECR. Temporomandibular dysfunction and craniocervical pain in professionals of the nursing area under work stress. Rev. CEFAC. 2016;18(2):439-48.

14. Fonseca DM, Bonfante G, Valle AL, Freitas SFT. Diagnóstico pela anamnese da disfunção craniomandibular. Rev Gaucha Odontol. 1994;42(1):23-8. 
15. Dworkin SF, LeResche L. Research diagnostic criteria for temporomandibular disorders: review, criteria, examinations and specifications, critique. J Craniomandib Disord. 1992;6(4):301-55.

16. Lucena LBS, Kosminsky M, Costa LJ, Góes PSA. Validation of the Portuguese version of the RDC/TMD Axis II questionnaire. Braz Oral Res. 2006;20(4):312-7.

17. Pereira $M$, Cruz EB, Domingues L, Duarte $S$, Carnide F, Fernandes R. Responsiveness and interpretability of the Portuguese version of the Neck Disability Index in patients with chronic neck pain undergoing physiotherapy. Spine. 2015;40(22):E1180-6.

18. Stegenga B, de Bont LG, de Leeuw R, Boering G. Assessment of mandibular function impairment associated with temporomandibular joint osteoarthrosis and internal derangement. $\mathrm{J}$ Orofac Pain. 1993;7(2):183-95.

19. Chaves TC, Oliveira AS, Grossi DB. Principais instrumentos para avaliação da disfunção temporomandibular, parte I: índices e questionários; uma contribuição para a prática clínica e de pesquisa. Fisioter. Pesqui. 2008;15(1):92-100.

20. Vernon H, Mior S. The Neck Disability Index: a study of reliability and validity. J Manipulative Physiol Ther. 1991;14(7):409-15.

21. Cook C, Richardson JK, Braga L, Menezes A, Soler $X$, Kume $P$ et al. Cross-cultural adaptation and validation of the Brazilian Portuguese version of the Neck Disability Index and Neck Pain and Disability Scale. Spine. 2006;31(14):1621-7.

22. Steenks MH, Wijer ADE. Disfunções da articulação temporomandilar. 1 ed. São Paulo: Santos, 1996.

23. Donnarumma MDC, Muzilli CA, Ferreira C, Nemr K. Disfunções temporomandibulares: sinais, sintomas e abordagem multidisciplinar. Rev. CEFAC. 2010;12(5):788-94.

24. Portinho CP, Collares MVM, Faller GJ, Fraga MM, Pinto RA. Perfil dos pacientes com disfunção temporomandibular. Arq Catarin Med. 2012;41(Supl. 1):95-9.

25. Ferreira CLP, Silva MAMR, Felício CM. Signs and symptoms of temporomandibular disorders in women and men. CoDAS. 2016;28(1):17-21.

26. Ciancaglini R, Testa M, Radaelli G. Association of neck pain with symptoms of temporomandibular dysfunction in the general adult population. Scand J Rehabil Med. 1999;31(1):17-22.
27. Torres F, Campos LG, Fillipini HF, Weigert KL, Vecchia GFD. Efeitos dos tratamentos fisioterapêutico e odontológico em pacientes com disfunção temporomandibular. Fisioter Mov. 2012;25(1):117-25.

28. Biasotto-Gonzalez DA, Andrade DV, Gonzalez TO, Martins MD, Fernandes KPS, Corrêa JCF et al. Correlação entre disfunção temporomandibular, postura e qualidade de vida. Rev Bras Crescimento Desenvol Hum. 2008;18(1):79-86.

29. Nunes AM, Martinez EM, Lopes PRR, Bittencourt MAV, Canedo PMM. Associação entre flexibilidade da cadeia muscular posterior e severidade de disfunção temporomandibular. Rev Ciênc Méd Biol. 2015;14(3):394-9.

30. Menezes MS, Bussadori SK, Fernandes KPS, Biasotto-Gonzalez DA. Correlação entre cefaléia e disfunção temporomandibular. Fisioter. Pesqui. 2008;15(2):183-7.

31. Milanesi JM, Weber P, Pasinato F, Corrêa ECR. Severidade da desordem temporomandibular e sua relação com medidas cefalométricas craniocervicais. Fisioter Mov. 2013;26(1):79-86.

32. Correia LMF, Guimarães AS, Teixeira ML, Rodrigues LL. Evaluation of body painful areas in patients with muscular temporomandibular disorder: a retrospective study. Rev Dor. 2015;16(4):249-53.

33. Tosato JP, Caria PHF. Electromyographic activity assessment of individuals with and without temporomandibular disorder symptoms. J Appl Oral Sci. 2007;15(2):152-5.

34. Da Costa DR, De Lima Ferreira AP, Pereira TA, Porporati AL, Conti PC, Costa YM et al. Neck disability is associated with masticatory myofascial pain and regional muscle sensitivity. Arch Oral Biol. 2015;60(5):745-52.

35. Silva GR, Martins PR, Gomes KA, Mambro TR, Abreu NS. O efeito de técnicas de terapias manuais nas disfunções craniomandibular. Rev Bras Cien Med Saúde. 2011;1(1):17-22.

36. Oliveira KB, Pinheiro ICO, Freitas DG, Gualberto HD, Carvalho NAA. A abordagem fisioterapêutica na disfunção da articulação temporomandibular: revisão de literatura. Med Reabil. 2010;29(3):61-4.

37. Rosa GMMV, Serafim AD, Bitencourt H, Varella PO, Maia PM, Gaban GA et al. Análise dos sinais e sintomas de desordem crânio-cervical em uma paciente portadora de disfunção têmporomandibular: um estudo de caso. Rev Inspirar Mov Saúde. 2011;3(5):16-20. 
38. Viana MO, Lima EICBMF, Menezes JNR, Olegario NBC. Avaliação de sinais e sintomas da disfunção temporomandibular e sua relação com a postura cervical. Rev Odontol UNESP. 2015;44(3):125-30.

39. Armijo Olivo S, Magee DJ, Parfitt M, Major P, Thie NM. The association between the cervical spine, the stomatognathic system, and craniofacial pain: a critical review. J Orofac Pain. 2006;20(4):271-87.

40. Weber P, Corrêa ECR, Ferreira FS, Soares JC, Bouzan GP, Silva AMT. Frequência de sinais e sintomas de disfunção cervical em indivíduos com disfunção temporomandibular. J Soc Bras Fonoaudiol. 2012;24(2):134-9. 